\title{
Identification and Field Assay of Two Aggregation Pheromone Components Emitted by Males of the Bark Beetle Polygraphus punctifrons (Coleoptera: Curculionidae)
}

\author{
Rizan Rahmani ${ }^{1}$ • Erika A. Wallin ${ }^{1} \cdot$ Lina Viklund $^{1} \cdot$ Martin Schroeder $^{2} \cdot$ Erik Hedenström $^{1}$ (D)
}

Received: 8 November 2018 / Revised: 7 February 2019 / Accepted: 14 February 2019 / Published online: 23 February 2019

(C) The Author(s) 2019

\begin{abstract}
The bark beetle Polygraphus punctifrons (Coleoptera: Curculionidae) is a species that feeds on Norway spruce (Picea abies) and is found in the Northern parts of Europe and Russia. The release of volatile organic compounds (VOCs) produced by males and females of $P$. punctifrons when the beetles bore into spruce stem sections in a laboratory environment was studied using solid phase microextraction (SPME). The sampled VOCs emitted by boring beetles were analysed by gas chromatography and mass spectrometry (GCMS). (+)-2-[(1R,2S)-1-Methyl-2-(prop-1-en-2-yl)cyclobutyl]ethanol [(+)-(1R,2S)-grandisol] and (-)-(R)-1-isopropyl-4-methyl-3-cyclohexen-1-ol [(-)-(R)-terpinen-4-ol] were identified to be male specific volatiles. The identity of the compounds was confirmed by comparison with synthetic samples. Field trials with synthetic compounds in Sweden showed that racemic grandisol per se was strongly attractive for both males and females, while $(-)-(R)$-terpinen-4-ol was not. Further, when adding $(-)-(R)$-terpinen-4-ol to rac-grandisol, a synergistic effect was observed as the trap catch of $P$. punctifrons was fourfold. $(-)-(R)$-Terpinen-4-ol by its own did not attract P. punctifrons but Polygraphus poligraphus, and the latter was also attracted to traps baited with a 10:90 mixture of the two compounds. Thus, we have identified $(+)-(1 R, 2 S)$-grandisol as a main component and $(-)-(R)$-terpinen-4-ol as a minor component of the aggregation pheromone of $P$. punctifrons. This opens future possibilities to monitor and, if necessary, manage populations of $P$. punctifrons.
\end{abstract}

Keywords Preparative fraction collection · Enantiomeric separation · SPME $\cdot(+)-(1 R, 2 S)$-Grandisol $\cdot(-)-(R)$-Terpinen-4-ol Picea abies

\section{Introduction}

Besides bark beetle species in the genera Dendroctonus and Ips, species of other bark beetle genera may cause considerable tree mortality. One example is the genus Polygraphus. In North America, P. rufipennis can kill black spruce (Bowers et al. 1991), and in Russia, the invasive P. proximus, originating from the most eastern part of Russia, have killed large numbers of

Electronic supplementary material The online version of this article (https://doi.org/10.1007/s10886-019-01056-6) contains supplementary material, which is available to authorized users.

Erik Hedenström

erik.hedenstrom@miun.se

1 Eco-Chemistry, Department of Chemical Engineering, Mid Sweden University, SE-851 70 Sundsvall, Sweden

2 Department of Ecology, Swedish University of Agricultural Sciences, Box 7044, SE-750 07 Uppsala, Sweden
Siberian fir (Kerchev 2014 and references therein). In Sweden, three Polygraphus species occur: P. poligraphus, P. punctifrons, and $P$. subopacus. P. poligraphus is distributed over the whole country, while the other two species occur in more northern parts. All three species reproduce in Norway spruce and are polygamous (one male and several females in the gallery systems). P. poligraphus is known to kill spruce trees during warm and dry summers (Lekander 1959; Hande 1979). Central Sweden recently experienced a large bark beetle outbreak, and at least 3 million $\mathrm{m}^{3}$ of timber were killed between 2008 and 2011 (Wulff, personal communication). Unexpectedly, not only I. typographus but also $P$. poligraphus and to some extent also $P$. punctifrons and P. subopacus were present in many of the killed trees (Schroeder and Wulff, personal communication). Thus, it is important to increase the knowledge of the biology of these species.

Tree-killing bark beetles (and their associated microorganisms) attacking living trees are confronted with diverse tree defence mechanisms (Franceschi et al. 2005; Krokene 2015). 
Thus, to overcome tree defences, a coordinated mass attack of beetles is necessary (Berryman 1982; Mulock and Christiansen 1986). When bark beetles bore into trees, they produce aggregation pheromones from precursors in the tree or de novo, which coordinates mass attacks of beetles (Blomquist et al. 2010; Tittiger and Blomquist 2016). In Polygraphus, it is the male that initiates the attack and produces the aggregation pheromone. So far, pheromones have been identified for P. poligraphus (Rahmani et al. 2015; Schurig et al. 1985) and P. rufipennis (Bowers et al. 1991).

In the present study, we identified $(+)-(1 R, 2 S)$-grandisol, and $(-)-(R)$-terpinen-4-ol as components of the aggregation pheromone of male $P$. punctifrons. The obtained results may have practical applications for the management and monitoring of $P$. punctifrons.

\section{Methods and Materials}

\section{Insects}

The $P$. punctifrons used in pheromone studies in 2015 originated from naturally colonised material collected in the province of Medelpad, Västernorrlands län (Sweden).

The insects used for laboratory experiments in 2018 were also caught at a location in Medelpad. Traps baited with racemic grandisol were used, and insects were collected after four to seven days of trapping and were stored in the refrigerator until they were used.

\section{VOC Sampling on SPME and GCMS Analysis}

Spruce stem sections, with 10 to $15 \mathrm{~cm}$ in diameter, were cut one to three weeks before they were used in experiments and during that time stored at $5^{\circ} \mathrm{C}$. Newly emerged $P$. punctifrons males and females were placed on the stem sections in $1.5 \mathrm{ml}$ Eppendorf microtubes (Sarstedt, Nümbercht, Germany), which were nailed on to the stem sections to collect volatiles released from the holes bored by the colonising beetles. In all of the experiments, an SPME fibre (pink or yellow - see below) was placed in the cut end of the microtube, and the gap between the SPME fibre and the opening was sealed with aluminium foil. All experiments were performed in the laboratory during April-July 2015 and August 2018 and at room temperature $\left(20-22{ }^{\circ} \mathrm{C}\right)$. The stem sections were exposed to natural daylight for $6 \mathrm{~h}$ between 09:00 and 15:00 and otherwise kept without direct natural daylight. VOC sampling for $1 \mathrm{~h}$ using an SPME fibre conditioned for $10 \mathrm{~min}$ at $250{ }^{\circ} \mathrm{C}$ before sampling, and GCMS analysis was normally performed once per day in each experiment.

In 2015, a total of 45 insects were separately introduced into Eppendorf microtubes nailed on three stems of Norway spruce. Fifteen insects were introduced to each stem, six females and nine males on the first stem (21-23 April), seven females and eight males to the second stem (21-23 April), and for the third stem (2 May) five females and ten males were introduced. In total nine males were followed by GCMS, and five of them produced the pheromone. In 2018, six males were introduced (20 August) to one stem, and three of them produced a pheromone that was analysed by GCMS. For background emission, each stem was manually drilled, and an empty Eppendorf tube was nailed onto the hole. VOCs were collected by using two different types of SPME fibres, $65-\mu \mathrm{m}$ polydimethylsiloxane/divinylbenzene (PDMS/DVB, Pink 57,326-U) and 30- $\mu \mathrm{m}$ polydimethylsiloxane (PDMS, Yellow 57,309-U) (Supelco, Bellefonte, PA, USA). A HewlettPackard 6890 N GC (Agilent Technologies, Santa Clara, CA, USA) using an HP 5973 mass spectrometer (MS) operating in electron impact (EI, $70 \mathrm{eV}$ ) ionisation mode for detection was used to analyse the SPME samples. The mobile phase (flow rate $=1.0 \mathrm{~mL} / \mathrm{min}$ ) was helium, the split $/$ splitless injector was operated in splitless mode at $250{ }^{\circ} \mathrm{C}$, the transfer line was maintained at $230^{\circ} \mathrm{C}$, and the auxiliary temperature was set to $200{ }^{\circ} \mathrm{C}$.

Different types of columns were applied including a polar column VF-23 ms $(30 \mathrm{~m} \times 0.25 \mathrm{~mm}$ i.d. and $0.25 \mu \mathrm{m}$ film thickness; Agilent J\&W Scientific, Folsom, CA, USA), the oven temperature was programmed from $50{ }^{\circ} \mathrm{C}$ after $2 \mathrm{~min}$, then at $5{ }^{\circ} \mathrm{C} / \mathrm{min}$ to $230{ }^{\circ} \mathrm{C}$ and held for $10 \mathrm{~min}$. The second column was a mid-polar HP-5 ms column $(30 \mathrm{~m} \times 0.25 \mathrm{~mm}$ i.d., $0.25 \mu \mathrm{m}$ film thickness; Agilent J\&W Scientific, Folsom, CA, USA), the oven temperature was programmed from $50{ }^{\circ} \mathrm{C}$ after $2 \mathrm{~min}$, then at $10{ }^{\circ} \mathrm{C} / \mathrm{min}$ to $230{ }^{\circ} \mathrm{C}$ and held for $10 \mathrm{~min}$. In addition, an enantioselective column of BETA $\mathrm{DEX}^{\mathrm{TM}} 225(30 \mathrm{~m} \times 0.25 \mathrm{~mm}$ i.d. and $0.25 \mu \mathrm{m}$ film thickness, Supelco, Bellefonte, PA, USA) was used with an initial temperature at $50{ }^{\circ} \mathrm{C}$, held for $2 \mathrm{~min}$, then increased to $200^{\circ} \mathrm{C}$ at $5^{\circ} \mathrm{C} / \mathrm{min}$. Desorption time for the fibre was $5 \mathrm{~min}$.

The raw MS data was analysed using the Chemstation (D.03.00.611) program (Agilent), and compounds were identified by comparing fragmentation patterns observed in the mass spectra with literature data and the NIST MS 2.0 mass spectral libraries with reverse and forward match values. The identities of assigned structures were also secured by comparing retention times and mass spectra of the natural products with those of synthetic references.

\section{Preparative Enantiomeric Separation and Collection of (+)-(1R,2S)-Grandisol and (-)-(1S,2R)-Grandisol Using a PFC Connected to a GCFID}

Preparative enantiomeric GC separation of racemic grandisol was performed on an Agilent 7890A GCFID (Santa Clara, CA, USA) equipped with an enantioselective semipreparative column (Rt- $\beta$ DEXsm $30 \mathrm{~m} \times 0.32 \mathrm{~mm}$ i.d., $0.25 \mu \mathrm{m}$ film thickness, Restek, Bellefonte, PA, USA). For 
the oven temperature program used for separation and collection of the enantiomers, the temperature was initially $100^{\circ} \mathrm{C}$, then increased to $150^{\circ} \mathrm{C}$ at $3{ }^{\circ} \mathrm{C} / \mathrm{min}$. The gas chromatograph was run with a constant flow of $2 \mathrm{~mL} / \mathrm{min}$ of helium with a PFC switch temperature of $210^{\circ} \mathrm{C}$, transfer line temperature of $200^{\circ} \mathrm{C}$, and two $1 \mu \mathrm{L}$ glass fraction collectors. In each run, $1 \mu \mathrm{L}$ of samples were injected in splitless mode.

Optical rotation measurements of the separated samples were carried out on a Perkin-Elmer 341 Polarimeter $(\mathrm{D}=$ $589 \mathrm{~nm}$, Na lamp, $1 \mathrm{dm}$ cell) and are reported in degrees.

\section{Chemicals}

$n$-Hexane (HPLC grade, Sigma-Aldrich, Schnelldorf, Germany) was used for LC purification and $n$-nonane (GC grade, Sigma-Aldrich, Schnelldorf, Germany) as solvent in field trials 2016. Racemic grandisol (Grandlure I) was purchased from Bedoukian Research (Danbury, CT, USA), and $(-)-(R)$-terpinen-4-ol (50\% ee) was purchased from TCI (Portland, OR, USA). Enantiomerically pure $(-)-(R)-$ terpinen-4-ol ( $>99 \%$ ee) was obtained by converting commercially available $(-)-(R)$-terpinen-4-ol $(50 \%$ ee) to its $3,5-$ dinitrobenzoyl derivative, which was recrystallized in ethanol and then in isopropanol. The $(-)-(R)$-enantiomer was first enriched in solution and then in the crystals, and the 3,5-dinitrobenzoate was hydrolysed (full experimental details are presented in the supplementary material).

Frontalin was purchased from Contech (Delta, BC, Canada) and Synergy Semiochemicals (Burnaby, BC, Canada).

A mixture of racemic grandisol and racemic fragranol was synthesised from cyclopropylphenylsulfide and 4-(benzyloxy)butane-2-one according to the method of Bernard et al. 2003 (Scheme 1). Full experimental details are presented in the supplementary material.

For field studies, racemic grandisol and enantiomerically pure (-)-(R)-terpinen-4-ol (> 99\% ee) were used. In 2015, the average release rate of grandisol from the dispensers was $12 \mu \mathrm{g} /$ day. This was determined as an average weight loss during 16 weeks in a well ventilated laboratory at $20-22{ }^{\circ} \mathrm{C}$. In 2016, the average release rates from the dispensers were $0.29 \mathrm{mg} /$ day for grandisol, $0.038 \mathrm{mg} /$ day for terpinen-4-ol, and $0.38 \mathrm{mg} /$ day for frontalin. This was determined as an average weight loss during the field experiment. The release rate of $(-)-(R)$-terpinen-4-ol was approximately $10 \%$ of the release rate of racemic grandisol to approximate the proportions seen in the insect, which was roughly estimated by comparing GC peak areas from insect samples.

\section{Field Tests}

Two field experiments were conducted in Sweden in 2015 and 2016 in the province of Medelpad, Västernorrlands län
(Sweden). Black Ecotraps (Fytofarm Ltd.) with collection jars for dry catches were used. The experiments were conducted in spruce dominated forests at 10 separate locations for each year. Three of the locations were used in both 2015 and 2016, while the other seven locations were changed. Traps were spaced at least $30 \mathrm{~m}$ apart from each other. In 2015, traps were baited July 7-9 and emptied weekly until September 2930. In 2016, traps were baited on June 21-23 and were emptied every week until August 30-31. However, due to large catches in 2016, only catches from the first week were counted and included in the analysis.

The experiment in 2015 included two treatments at ten locations: (1) $100 \mathrm{mg}$ of racemic grandisol in a $400 \mu \mathrm{l}$ polyethylene dispenser (Synergy Semiochemicals Corp.) and an empty dispenser as a control. Racemic grandisol was chosen for the experiment as it is commercially available.

In 2016, the field experiment included six treatments at ten locations: (1) $50 \mathrm{mg}$ of racemic grandisol, (2) $50 \mathrm{mg}$ of racemic frontalin, (3) $5 \mathrm{mg}$ of (-)-(R)-terpinen-4-ol (> 99\% ee), (4) $50 \mathrm{mg}$ of racemic grandisol with $50 \mathrm{mg}$ of racemic frontalin, (5) $50 \mathrm{mg}$ of racemic grandisol with $5 \mathrm{mg}$ of $(-)-(R)$-terpinen4-ol and (6) a control. (-)- $(R)$-Terpinen-4-ol was prepared in our laboratory and included in the field experiment because it is quantitatively a minor compound emitted by $P$. punctifrons males. Frontalin has been shown to increase the catches of $P$. poligraphus when added to the species' pheromone (Kohnle et al. 1985). Slightly modified "wick baits" were used as dispensers (Birgersson et al. 2012). The compound(s) for each bait was dissolved in $8 \mathrm{~mL}$ of $n$-nonane and placed in a $12 \mathrm{~mL}$ glass vial. The dissolved compound(s) were allowed to evaporate through a Teflon tube, $8 \mathrm{~cm} \times 1.5 \mathrm{~mm}$ i.d. which was lined with cotton yarn and inserted through a drilled hole in the lid of the vial.

In both years, the field studies were part of a larger study focused on evaluating attractants and repellants for P. poligraphus. Dispensers were weighed before and after the experiment in 2016 to estimate release rates, whereas in 2015 release rates were measured as an average weight loss during 16 weeks in a well ventilated laboratory at $20-22{ }^{\circ} \mathrm{C}$. Collected insects were stored in the freezer until identification could be done. Beetles were identified and sexed in the laboratory using a stereomicroscope (Sagitta) with 14-90 times magnification (Lekander 1959). In 2015, all insects were identified, but in 2016, due to the large number of Polygraphus caught and the time-consuming determination of Polygraphus species, a sample of 50 beetles per trap was investigated.

\section{Statistial Analyses}

Treatment effects were compared by analyzing the number of caught beetles, using a two-sided Student's T test assuming unequal variances. A paired test was used since the population size was expected to vary in the different locations. Each 
location was considered a replication and the significance level was set to $\alpha=0.05$. Statistical tests were performed in Microsoft Excel using built in functions. The average number of caught beetles per trap with a $95 \%$ confidence interval was also calculated.

\section{Results and Discussion}

\section{VOC Sampling on SPME and GCMS Analysis}

This work reports the characterisation of volatile chemicals emitted by P. punctifrons males and the identification of two compounds emitted by boring males. Five of the boring males that were followed by GCMS produced one compound in high amounts at retention time $15.61 \mathrm{~min}$ (Fig. 1a). The compound was absent in the spruce log (Fig. 1b) and not released by females (Fig. 1c). This interesting discovery prompted us to have a closer look at the identity of this male-specific compound and also on a smaller peak emitted by males at retention time $12.20 \mathrm{~min}$. NIST MS search 2.0 library and reverse and forward match values were used to extract the best hits when comparing observed fragmentation patterns in the mass spectra of the unidentified compounds. For the peak eluting at $15.61 \mathrm{~min}$ the two most promising hits were suggested as grandisol (with a forward match value of 955 and a reverse match value of 955) and fragranol (with a forward match value of 814 and a reverse match value of 921). Consequently, the identity for the compound emitted in high amounts was nearly equally probabable for the two diastereomeric monoterpenes grandisol and fragranol.

For the male-specific compound at retention time 12.20 min forward match values of 919 and reverse match 919 was obtained, and the highest rated hit correlated to 1- isopropyl-4-methyl-3-cyclohexen-1-ol resp. p-menth-1-en-4ol, which is terpinen-4-ol.

The identities of the two compounds were further supported, when performing GCMS analysis using both an HP-5 ms (not shown) and VF-23 ms column and comparing retention times for the two unknown volatiles (Fig. 2) with synthetic reference compounds. Overlap was obtained with terpinen-4ol and Grandlure I (grandisol) respectively.

\section{Synthesis}

The very similar mass spectra of grandisol and fragranol prompted us to synthesise a reference mixture containing both diastereomers in a known ratio according to an established reaction pathway (Bernard et al. 2003). The synthesis started (Scheme 1) from 4-(benzyloxy)butan-2-one (1) obtained via the reaction between deprotonated cyclopropyl phenyl sulphide (2) resulting in 4-(benzyloxy)-2-(1-(phenylthio)cyclopropyl)butan2-ol (3). 2-(2-(Benzyloxy)ethyl)-2-methylcyclobutan-1-one (4) was obtained after a ring expansion under acidic conditions (PTSA in benzene). Compound (4) underwent a WittigHorner reaction with triethyl phosphonopropionate $(60 \% \mathrm{NaH}$ in oil, TDA-1, THF and reflux) yielding ethyl $(Z)$ 2-(2-(2-(benzyloxy)ethyl)-2-methylcyclobutylidene)propanoate (5). Two subsequent reductions were performed; reduction of the conjugated double bond using $\mathrm{Mg}(\mathrm{s})$ in methanol and reduction of the ester with lithium aluminumhydride in THF. The obtained 2-(2-(2-(benzyloxy)ethyl)-2-methylcyclobutyl)propan1-ol was transformed to the iodide (6) $\left(\mathrm{I}_{2}, \mathrm{PPh}_{3}\right.$, Imidazole, ACN) followed by dehydroiodination with silver fluoride in dry pyridine, yielding a 1:0.8 diastereomeric mixture (cis:trans) of ((2-(1-methyl-2-(prop-1-en-2-yl)cyclobutyl)ethoxy)methyl)benzene $(7,8)$. The final step was deprotection of the ((2-(1-methyl-2-(prop-1-en-2-yl)cyclobutyl)ethoxy)methyl)benzene performed with $\mathrm{Li} / \mathrm{NH}_{3}$ resulting in a 1:0.8 mix of

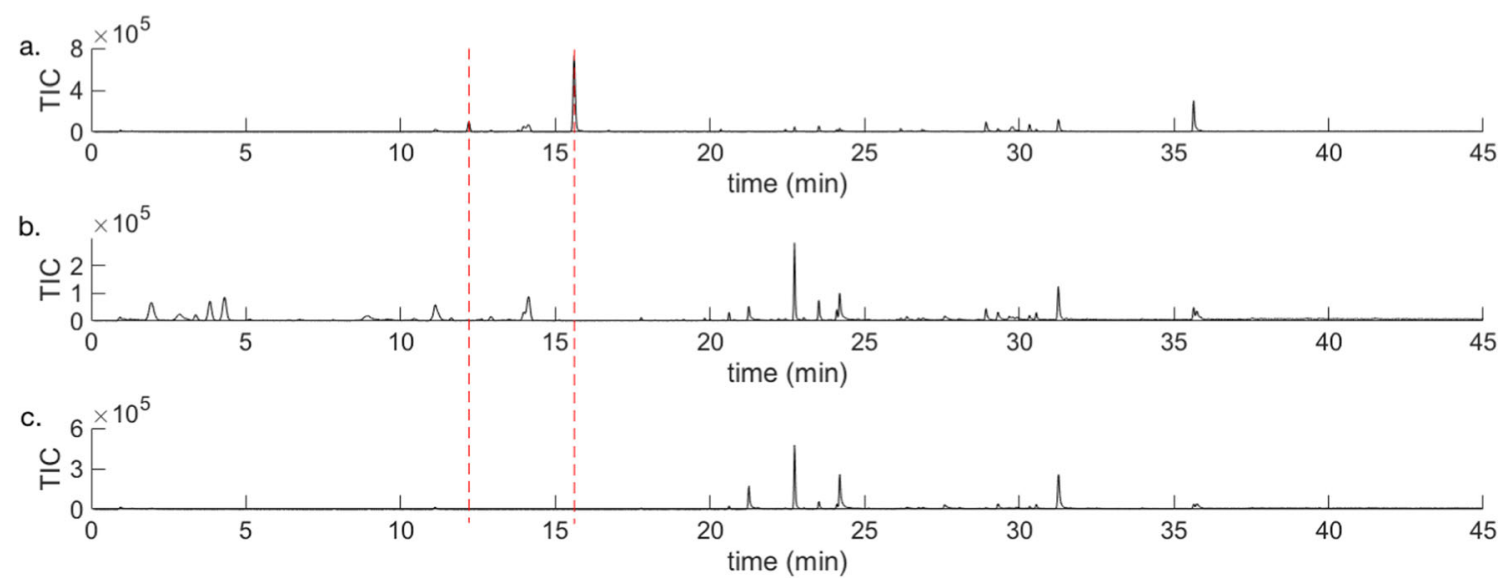

Fig. 1 GCMS analysis using a VF-23 ms column. GC/MS chromatogram of VOCs sampled by SPME (yellow fibre) a) from a representative boring male of $P$. punctifrons on a spruce stem section, $\mathbf{b}$ from a spruce stem with a representative boring female of $P$. punctifrons, $\mathbf{c}$ from a representative spruce stem that has been manually disturbed by drilling. The dashed red lines show that the compound at $12.20 \mathrm{~min}$ and the compound at $15.61 \mathrm{~min}$ are not found in the female and the background emission 


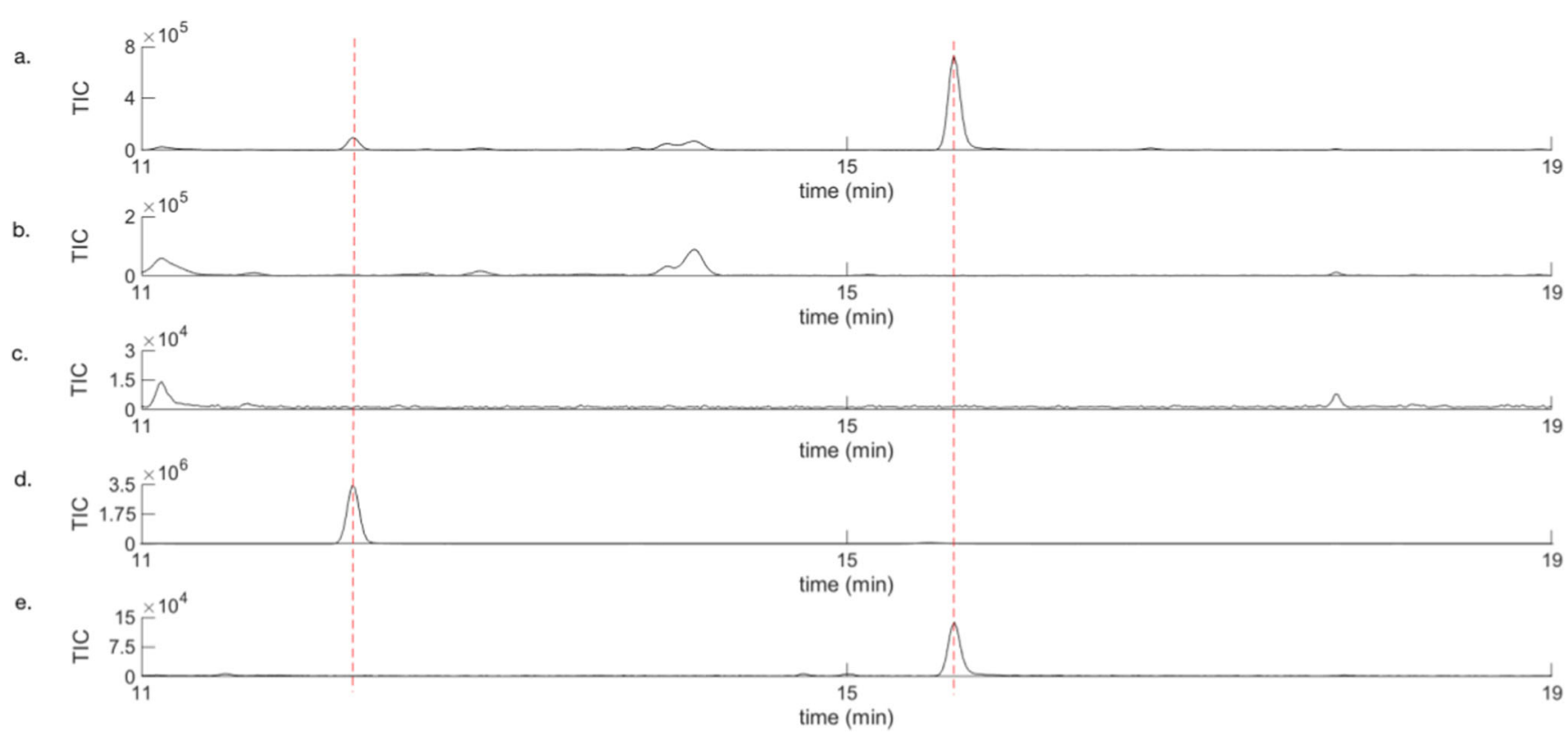

Fig. 2 GCMS analysis using a VF-23 ms column. Zoomed in parts of GCMS chromatograms of a) VOCs from a representative boring male of $P$. punctifrons on a spruce stem section sampled by SPME (yellow fibre), b VOCs from a spruce stem with a representative boring female of $P$.

grandisol and fragranol (as determined by GC). Column chromatography on silica resulted in a partial separation of the isomers, and three fractions were isolated. One fraction containing only grandisol, one small fraction with only fragranol and one fraction with a mixture of the isomers.

The synthesised mixture of diastereomers obtained after SPE was then analysed by GCMS on an HP- 5 ms column (Fig. 3) which separated grandisol and fragranol better than the VF-23 ms column.

The analysis presented in Fig. 3 conclusively confirmed the male specific compound to be grandisol as the retention times are the same as for grandisol in the synthetic mixture. When we compared the mass spectra from the male emitted compound, synthetic grandisol and fragranol, the spectra were almost identical (Fig. 4).

From our results above, we propose that males of $P$. punctifrons emit grandisol and terpinen-4-ol as a part of an aggregation pheromone. Grandisol was first identified in the cotton boll weevil, Anthonomus grandis (Gueldner et al. 1971) and since then also in several other beetle species but only once in a bark beetle, Pityophthorus pityographus (Francke et al. 1987). When sampling with SPME fibres (PDMS/DVB) the ratio of grandisol to terpinen-4-ol varied from 99:1 to 80:20 when comparing GC peak areas from the GCMS analysis of volatiles of different males.

\section{Enantiomeric Analysis of Male Emitted Grandisol and Terpinen-4-ol}

It remained to determine the enantiomeric composition of terpinen-4-ol and grandisol from the volatiles produced by punctifrons sampled by SPME (yellow fibre), c VOCs from a representative spruce stem that has been manually disturbed by drilling and then sampled by SPME (yellow fibre), $\mathbf{d}$ synthetic reference of terpinen-4-ol, $\mathbf{e}$ synthetic reference of Grandlure I (grandisol)

male $P$. punctifrons. Earlier work by Francke and Vité (1983), Schurig et al. (1985), and Rahmani et al. (2015) showed that males of $P$. poligraphus emit $(-)-(R)$-terpinen-4ol of high optical purity. The enantioselective analysis of the production of specific compounds from three $P$. punctifrons males revealed that also in this species only the $(-)-(R)$ terpinen-4-ol enantiomer is produced (Fig. 5a and d).

To investigate which enantiomer of grandisol males of $P$. punctifrons were emitting, pure synthetic enantiomers were needed for comparison of GC retention times. Instead of a complicated synthesis with many reaction steps and very low yield (Alibés et al. 1996), an alternative and less timeconsuming method was chosen: preparative gas chromatography (see, for example, Ravid et al. 1992; Kim et al. 2014). We decided to use a semi-preparative enantioselective GC column, Rt- $\beta$ DEXsm, to separate the grandisol enantiomers and then collect the pure enantiomers with a fraction collector (PFC). This semi-preparative column showed a different selectivity for the two compounds compared to the analytical BETA DEX ${ }^{\mathrm{TM}} 225$ column, resulting in a reversed elution order of the two enantiomers. Two experiments were run consisting of more than $500 \mathrm{GC}$ injections during two weeks, and two fractions were collected from each experiment and their optical rotation $[\alpha]_{\mathrm{D}}{ }^{20}$ were measured in $n$-hexane at $20{ }^{\circ} \mathrm{C}$. Experiment one gave +0.2 for fraction one and -0.5 for fraction two, while experiment two gave +0.3 for fraction one and -0.6 for fraction two. The optical rotation sign in combination with enantioselective $\mathrm{GC}$ was then used to assign the absolute configuration to the male produced natural grandisol. In Fig. 5a-c it is shown that the enantiomer with 
<smiles>CC(=O)CC[O+]Br</smiles>

1<smiles>CC(O)(CCOCc1ccccc1)C1([Sb])CC1C1CC1</smiles>

3

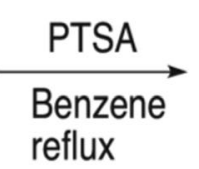

reflux<smiles>CC1(CCOc2ccccc2)CCC1=O</smiles>

4<smiles>CCOC(=O)C(C)P(=O)(OCC)OCC</smiles>

$\mathrm{NaH}$

TDA-1 reflux

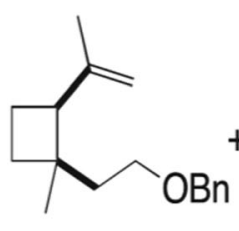

7

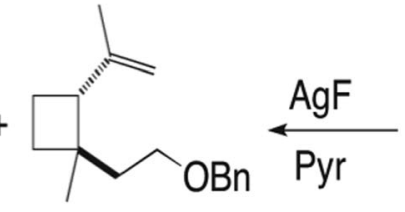

8

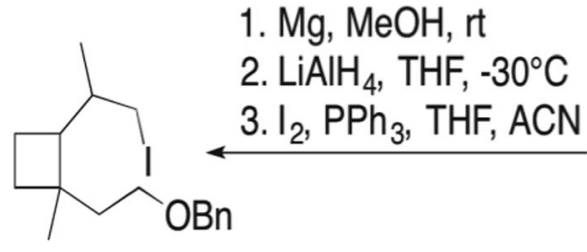

6<smiles>CCOC(=O)C(C)=C1CCC1(C)CCOCc1ccccc1</smiles>

5

$$
\begin{aligned}
& \mathrm{Li} / \mathrm{NH}_{3} \\
& -78^{\circ} \mathrm{C}
\end{aligned}
$$<smiles>C=C(C)[C@@H]1CCC1(C)CCO</smiles>

rac-Grandisol

rac-Fragranol

\section{$1: 0.8$ \\ according to $\mathrm{GC}$}

Scheme 1 The synthetic pathway to produce a 1:0.8 mixture of racemic grandisol and racemic fragranol

the optical rotation sign of $(+)$ is the one produced by males of P. punctifrons. The enantiomeric purity of the (+)-PFC-fractions was $95.5 \%$, and the (-)-PFC-fractions was $25 \%$ ee. Thus, one major component (+)-(1R,2S)-grandisol (Fig. 6) and one minor component (-)-(R)-terpinen-4-ol (Fig. 6) have been detected in the SPME sampled volatiles of adult male P. punctifrons.

\section{Field Study}

During the summer of 2015, 643 P. punctifrons were caught in the $r a c$-grandisol baited traps at 10 locations in the province of Medelpad, and $61 \%$ of them were females (Table 1). Only 4 P. punctifrons were caught in the unbaited traps. The rac- grandisol baited traps caught significantly more beetles than the unbaited traps, both males (Student's T test, paired, twotailed, $P=0.03)$ and females $(P=0.04)$.

In 2016, 16,244 Polygraphus beetles were caught in total during one week at 10 locations (Table 2). Beetles were counted, and a subsample of 50 beetles per trap was identified, that is 500 beetles per treatment. The percentage of each species in the subsamples was used to estimate the average number of P. punctifrons and $P$. poligraphus caught per trap. For traps baited with rac-grandisol as well as traps baited with racgrandisol and frontalin, all beetles in the subsamples were $P$. punctifrons. It was confirmed once again that rac-grandisol baited traps caught more beetles than the control (Student's T test, paired, two-tailed, $P=0.001$ ). 
Fig. 3 Retention time for grandisol and fragranol on an HP$5 \mathrm{~ms}$ column. GCMS analysis of a) VOCs from a boring male of $P$. punctifrons on a spruce stem section sampled by SPME (pink fibre) and b) synthetic mixture after SPE of grandisol (r.t $=10.16 \mathrm{~min})$ and fragranol ( $r . t=10.20 \mathrm{~min})$

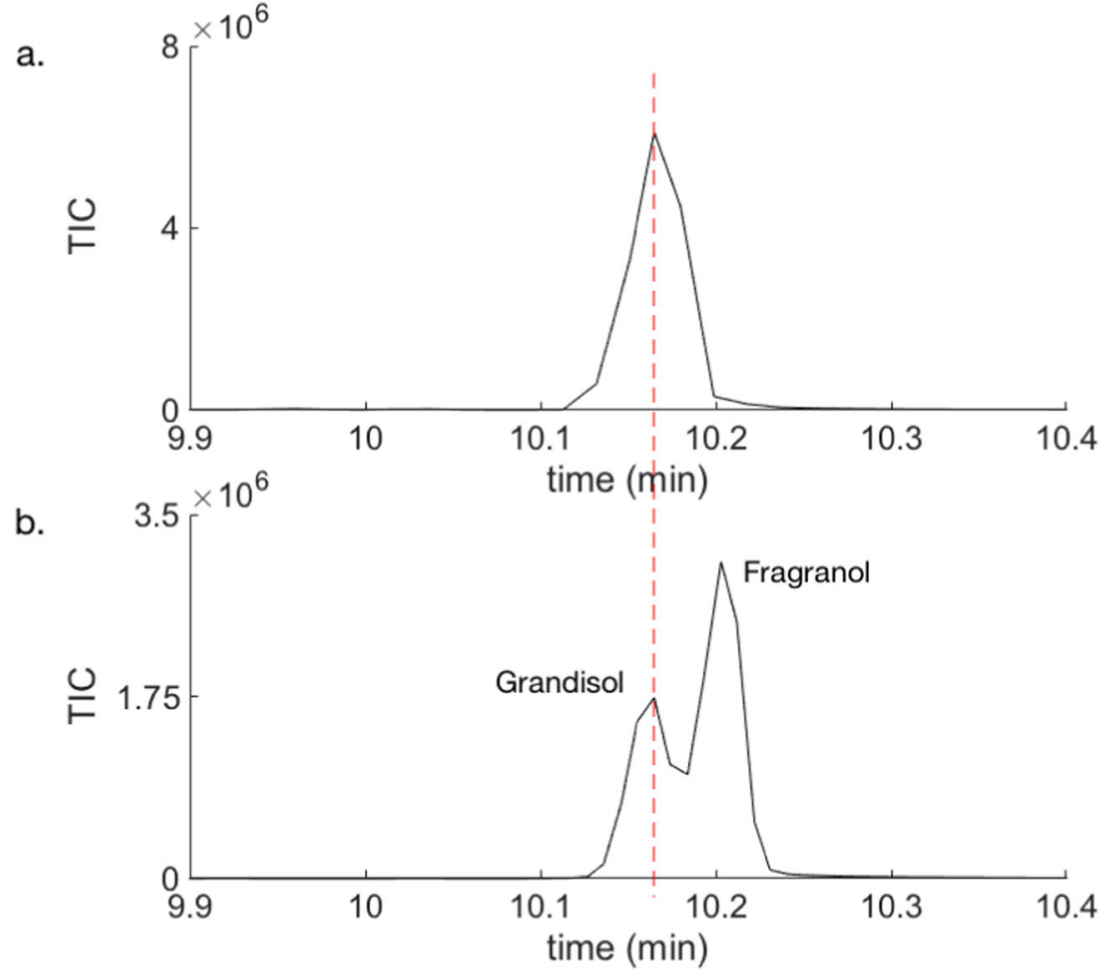

Traps baited with a mixture of rac-grandisol and frontalin did not catch significantly different numbers of beetles than traps baited with only rac-grandisol (Student's T test, paired, two-tailed, $P=0.61$ ). For $(-)-(R)$-terpinen-4-ol, all beetles in the subsamples were $P$. poligraphus. As expected, P. poligraphus was more attracted to its pheromone $(-)-(R)$-terpinen-4-ol than to the control (Student's $\mathrm{T}$ test, paired, two-tailed, $\mathrm{P}=$ $0,01)$. Traps baited with a mixture of rac-grandisol and $(-)-(R)$-terpinen-4-ol caught significantly more $P$. punctifrons than rac-grandisol baited traps (Student's T test, paired, two-tailed, $P=0.006)$ and possibly more $P$. poligraphus than $(-)-(R)$-terpinen-4-ol-baited traps, however, in the last case, the difference was not statistically significant (Student's $\mathrm{T}$ test, paired, two-tailed,
$P=0.051)$. The unbaited traps did not catch any beetles, and the frontalin baited traps caught only two beetles in total, both were $P$. poligraphus.

The large catches in 2016 were probably due to the higher release rate of racemic grandisol from the dispensers as compared to the release rates in 2015. This was possible due to the change of dispenser type, from polyethylene dispensers to "wick baits". It is likely that the populations of $P$. punctifrons varies from year to year, during the summer and between different sites, which may also partly explain the large difference in trap catches between 2015 and 2016.

Frontalin has been shown to increase catches of P. poligraphus when combined with its pheromone terpinen4-ol (Kohnle et al. 1985), but no such effect could be seen for
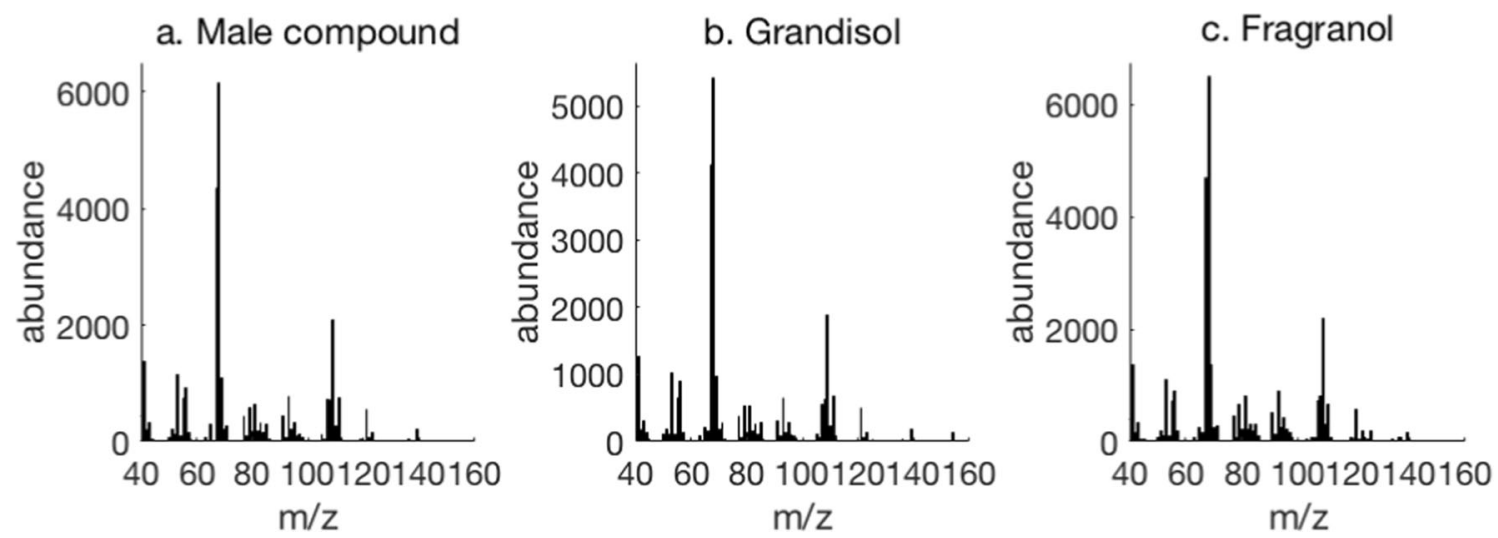

Fig. 4 Mass spectra for a) the peak from a representative $P$. punctifrons male, $\mathbf{b}$ synthetic grandisol, and $\mathbf{c}$ ) synthetic fragranol 
a.

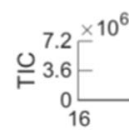

b.

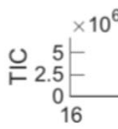

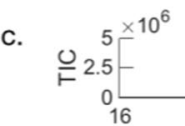

d.

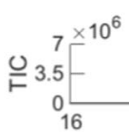

e.

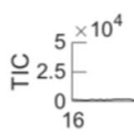

Fig. 5 Zoomed in part of chromatograms from the GCMS analysis on a chiral BETA DEX ${ }^{\mathrm{TM}} 225$ column. a VOCs released by a boring male of $P$. punctifrons on a spruce stem section sampled by SPME (pink fibre), b enantiomerically pure (+)-(1R,2S)-grandisol from PFC trap 1, c enriched

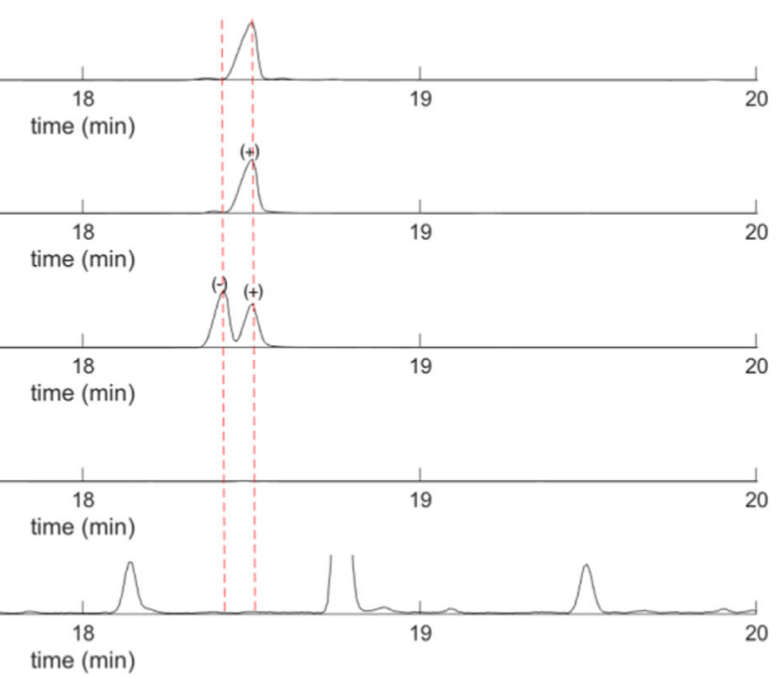

$(-)$-(1S,2R)-grandisol from PFC trap 2, d commercial (-)-(R)-terpinen-4ol showing $50 \%$ ee, e VOCs from a representative spruce stem that has been affected by manually drilling (sampled by SPME, pink fibre)<smiles>C=C(C)[C@H]1CC[C@]1(C)CCO</smiles><smiles>CC1=CC[C@@](O)(C(C)C)CC1</smiles>

Fig. 6 (+)-(1R,2S)-Grandisol(-)-(R)-Terpinen-4-ol

P. punctifrons in this study. However, the combination of racgrandisol and $(-)-(R)$-terpinen-4-ol seems to result in a synergistic effect when it comes to trap catches of $P$. punctifrons.

$(-)-(R)$-Terpinen-4-ol is also the pheromone of P. poligraphus (Francke and Vité 1983; Rahmani et al. 2015; Schurig et al. 1985), and it was shown that this species was also caught in the traps baited with rac-grandisol and $(-)-(R)$-terpinen-4-ol. The combination may be more attractive to $P$. poligraphus than $(-)-(R)$-terpinen-4-ol alone, but the difference was not statistically significant. Racemic grandisol alone did not attract $P$. poligraphus, based on our subsamples. These somewhat puzzling results indicate that rac-grandisol is not a repellent for $P$. poligraphus as might have been expected to differentiate the aggregation pheromones of the two species. A possibility is a missing component in the $P$. punctifrons aggregation pheromone that acts as a repellent for $P$. poligraphus or that a yet unknown compound is necessary to complete the aggregation pheromone of P. poligraphus (Francke and Vité 1983). Nevertheless, racemic grandisol may have a similar behavior modifying effect on this species as frontalin (Kohnle et al. 1985). Anyway, this interesting result is not the focus of this work but needs to be investigated further in the future.

Table 1 Trap catches of $P$. punctifrons, July 7-September 30,2015. Catches are presented as a total of males and females from the entire trapping period, and as a mean per trap with a $95 \%$ confidence interval $(95 \% \mathrm{CI})$. There were 10 replications in the experiment $(N=10)$

\begin{tabular}{|c|c|c|c|c|}
\hline \multirow[t]{2}{*}{ Treatment } & \multicolumn{2}{|c|}{ P. punctifrons female } & \multicolumn{2}{|c|}{ P.punctifrons male } \\
\hline & Total & Mean per trap $(95 \% \mathrm{CI}), N=10$ & Total & Mean per trap $(95 \% \mathrm{CI}), N=10$ \\
\hline rac-Grandisol & 392 & $39( \pm 36)$ & 251 & $25( \pm 22)$ \\
\hline Control & 3 & $0( \pm 1)$ & 1 & $0( \pm 0)$ \\
\hline
\end{tabular}


Table 2 Trap catches of Polygraphus beetles, June 21June 29, 2016. Catches are presented as a total and as a mean per trap for each species with a $95 \%$ confidence interval $(95 \% \mathrm{CI})$. Estimated numbers are based on the proportion of each species in subsamples of identified beetles. There were 10 replications in the experiment $(\mathrm{N}=10)$

\begin{tabular}{|c|c|c|c|c|}
\hline Treatment & $\begin{array}{l}\text { Polygraphus } \\
\text { spp. } \\
\text { Total }\end{array}$ & $\begin{array}{l}\text { Percentage } \\
\text { identified }\end{array}$ & $\begin{array}{l}\text { Estimated number of } \\
\text { P. punctifrons } \\
\text { Mean per trap }(95 \% \\
\text { CI), } N=10\end{array}$ & $\begin{array}{l}\text { Estimated number of } \\
\text { P. poligraphus } \\
\text { Mean per trap }(95 \% \\
\text { CI), } N=10\end{array}$ \\
\hline rac-Grandisol & 2489 & $20 \%$ & $249( \pm 125)$ & 0 \\
\hline Frontalin & 2 & $100 \%$ & 0 & $0( \pm 0)$ \\
\hline$(-)-(R)$-Terpinen-4-ol & 496 & $100 \%$ & 0 & $50( \pm 35)$ \\
\hline $\begin{array}{l}\text { rac-Grandisol } \\
\& \text { frontalin }\end{array}$ & 2300 & $21 \%$ & $230( \pm 105)$ & 0 \\
\hline $\begin{array}{l}\text { rac-Grandisol \& } \\
\quad(-)-(R) \text {-terpinen-4-ol }\end{array}$ & 10,957 & $4.8 \%$ & $950( \pm 414)$ & $146( \pm 122)$ \\
\hline Control & 0 & - & 0 & 0 \\
\hline
\end{tabular}

\section{Conclusion}

This report presents the first identification of two components in the male produced aggregation pheromone of $P$. punctifrons. One major component $(+)-(1 R, 2 S)$-grandisol and one minor component $(-)-(R)$-terpinen-4-ol have been detected in the SPME sampled volatiles of adult male $P$. punctifrons. The compounds were neither detected among the volatiles emitted by adult females nor in the background emission of Norway spruce logs. The two male-specific compounds were identified by comparison with synthetic standards using GCMS. The stereoisomeric composition of the natural products was assigned by using enantioselective GC. Field trials with synthetic compounds showed that racemic grandisol per se was strongly attractive to both males and females. Moreover, when adding (-)-(R)terpinen-4-ol to rac-grandisol in a ratio close to what we found when analysing the SPME fibres, a synergistic effect was observed as the trapcatch was fourfold. Our results may have practical utility for future management and monitoring of P. punctifrons.

Acknowledgements We are grateful for financial support from the European regional development funds, the county board of Västernorrland, the region of Jämtland/Härjedalen, the region of Västernorrland, and the Swedish Research Council for Environment, Agricultural Sciences, and Spatial Planning (Formas) (grant no. 9422016-11). We also thank SCA Skog AB for putting suitable spruce forests at our disposal, Skogsstyrelsen, Sundsvall for lending Ecotraps to the project, Dragos Cocos and Helena Johansson for providing and identifying some of the beetles for the pheromone studies and professor Göran Birgersson for introducing us to "wick baits".

Open Access This article is distributed under the terms of the Creative Commons Attribution 4.0 International License (http:// creativecommons.org/licenses/by/4.0/), which permits unrestricted use, distribution, and reproduction in any medium, provided you give appropriate credit to the original author(s) and the source, provide a link to the Creative Commons license, and indicate if changes were made.

\section{References}

Alibés R, Bourdelande JL, Font J, Parella T (1996) Highly efficient and diastereoselective approaches to (+)- and (-)-grandisol. Tetrahedron 52:1279-1292. https://doi.org/10.1016/0040-4020(95)00958-2

Bernard AM, Frongia A, Secci F, Delogu G, Ollivier J, Piras PP, Salaun J (2003) Stereospecific palladium(0)-catalyzed reduction of 2cyclobutylidenepropyl esters. A versatile preparation of diastereomeric monoterpenoids: $( \pm)$-fragranol and $( \pm)$-grandisol. Tetrahedron 59:9433-9440. https://doi.org/10.1016/j.tet.2003.09.074

Berryman AA (1982) Biological control, thresholds and pest outbreaks. Environ Entomol 11:544-549. https://doi.org/10.1093/ee/11.3.544

Birgersson G, Dalusky MJ, Espelie KE, Berisford CW (2012) Pheromone production, attraction, and interspecific inhibition among four species of Ips bark beetles in the southeastern USA. Psyche 6:1-14. https://doi.org/10.1155/2012/532652

Blomquist GJ, Figueroa-Teran R, Aw M, Song M, Gorzalsi A, Abott NL, Chang E, Tittiger C (2010) Pheromone production in bark beetles. Insect Biochem Mol Biol 40:699-712. https://doi.org/10.1016/j. ibmb.2010.07.013

Bowers WW, Gries G, Borden JH, Pierce HD Jr (1991) 3-Methyl-3buten-1-ol: an aggregationpheromone of the four-eyed spruce bark beetle, Polygraphus rufipennis (Kirby) (Coleoptera: Scolytidae). J Chem Ecol 17:1989-2002. https://doi.org/10.1007/BF00992583

Franceschi VR, Krokene P, Christiansen E, Krekling T (2005) Anatomical and chemical defenses of conifer bark against bark beetles and other pests. New Phytol 167:353-376. https://doi.org/10. $1111 / \mathrm{j} .1469-8137.2005 .01436 . x$

Francke W, Vité JP (1983) Oxygenated terpenes in pheromone systems of bark beetles. J Appl Entomol 96:146-156. https://doi.org/10.1111/j. 1439-0418.1983.tb03655.x

Francke W, Pan ML, König WA, Mori K, Puapoomchareon P, Heuer H, Vité JP (1987) Identification of 'pityol' and 'grandisol' as pheromone components of the bark beetle, Pityophthorus pityographus. Naturwissenschaften 74:343-345. https://doi.org/10.1007/ BF00367933 
Gueldner RC, Tumlinson JH, Hardee DD, Thompson AC, Hedin PA, Minyard JP (1971) Identification and synthesis of the four compounds comprising the boll weevil sex attractant. J Organomet Chem 36:2616-2621. https://doi.org/10.1021/jo00817a012

Hande L (1979) Granbarkbillen. Granbarkbille- og grantørkesituasjonen i Sør-Norge. NOU (Norges offentlige utredninger). Landbruks departemented, Oslo, p 71 (in Norwegian)

Kerchev IA (2014) On monogyny of the four-eyed fir bark beetle Polygraphus proximus Blandf. (Coleoptera, Curculionidae: Scolytinae) and its reproductive behavior. Entomol Rev 94:10591066. https://doi.org/10.1134/S0013873814080028

Kim L, Tuck KL, Marriott PJ (2014) Preparative gas chromatography (prep-GC). In: Reference module in chemistry, molecular sciences and chemical engineering. Elsevier, Amsterdam

Kohnle U, Francke W, Bakke A (1985) Polygraphus poligraphus (L) response to enantiomers of beetle specific terpene alcohols and a bicyclic ketal. J Appl Entomol 100:5-8. https://doi.org/10.1111/j. 1439-0418.1985.tb02748.x

Krokene P (2015) Conifer defense and resistance to bark beetles. In: Vega FE, Hofstetter RW (eds) Bark beetles - biology and ecology of native and invasive species, 1st edn. Academic press, Cambridge, pp 107-208

Lekander B (1959) Der doppeläugige Fichtenbastkäfer Polygraphus poligraphus L. - Ein Beitrag zur Kenntnis seiner Morphologie,
Anatomie, Biologie und Bekämpfung. Meddelanden från Statens Skogsforskningsinstitut 48:1-127

Mulock P, Christiansen E (1986) The threshold of successful attack by Ips typographus on Picea abies: a field experiment. Forest Ecol Manag 14:125-132. https://doi.org/10.1016/0378-1127(86)90097-6

Rahmani R, Hedenström E, Schroeder M (2015) SPME collection and GC-MS analysis of volatiles emitted during the attack of male Polygraphus poligraphus (Coleoptera, Curcolionidae) on Norway spruce. Z Naturforsch C 70:265-273. https://doi.org/10.1515/znc2015-5035

Ravid U, Putievsky E, Katzir I, Ikan R (1992) Determination of the enantiomeric composition of terpinen-4-ol in essential oils using a permethylated $\beta$-cyclodextrin coated chiral capillary column. Flav Fragr J 7:49-52. https://doi.org/10.1002/ffj.2730070112

Schurig V, Leyrer U, Kohnle U (1985) Enantiomer composition and absolute configuration of terpinen-4-ol from the bark beetle Polygraphus poligraphus. Naturwissenschaften 72:211-211. https://doi.org/10.1007/BF01195767

Tittiger C, Blomquist GJ (2016) Pheromone production in pine bark beetles. Vol. 50. In: Tittiger C, Blomquist GJ (eds) Advances in insect physiology - pine bark beetles. Academic Press, Cambridge, pp 235-263 